\title{
Vivax malaria in an Amazonian child with dilated cardiomyopathy
}

\author{
Antonio C Martins', Jamille B Lins ${ }^{2}$, Luana MN Santos², Licia N Fernandes ${ }^{3}$, Rosely S Malafronte ${ }^{3}$, Teresa C Maia ${ }^{2}$, \\ Melissa CV Ribera², Ricardo B Ribera² and Monica da Silva-Nunes ${ }^{1 *}$
}

\begin{abstract}
A child living in the Brazilian Amazon region who had had vivax malaria at the age of 11 months was admitted three months later with a history of progressive dyspnoea and fever, which culminated in respiratory distress and severe dilated cardiomyopathy at hospital admission in a malaria-free area. She received treatment for cardiac insufficiency and was tested for malaria with two thick blood smears, which were negative. There was general improvement of cardiorespiratory function in the next two weeks, but in the third week of hospital admission, there was re-appearance of fever, severe anaemia, severe plaquetopaenia, and respiratory distress. A third thick blood smear was positive for Plasmodium vivax mono-infection, which was confirmed by molecular methods. A serological panel with the most prevalent infectious agents known to cause myocarditis was performed, and specific anti-cytomegalovirus (CMV) IgM and elevated levels of anti-CMV IgG were also detected in the serum. After treatment for malaria, there was improvement of respiratory distress, although cardiac function did not recover. She was discharged home with drugs for cardiac insufficiency and is currently under follow-up with a paediatric cardiologist as an outpatient. This report presents a young child with several episodes of vivax malaria who suffers from cardiac insufficiency, probably related to CMV-induced myocarditis.
\end{abstract}

Keywords: Vivax malaria, Amazon, Dilated cardiomyopathy, Cardiac dysfunction, Cytomegalovirus infection

\section{Background}

Vivax malaria is an important disease responsible for up to 400 million infections in endemic areas of Asia, Latin America, and some parts of Africa. In recent years, it has been shown that this so-called benign malaria can result in severe presentation with multiple organ dysfunction and life-threatening disease. The majority of severe vivax malaria cases have been reported in India [1-4], but many cases occurred in other countries where there is active transmission, such as Ethiopia [5], Sudan [6], Cambodia [7], Colombia [8], and Brazil [9-12]. Criteria for diagnosing severe vivax malaria, as opposed to severe falciparum malaria, are still not clearly defined, since some biological features of these two parasites are different, and in the meantime the WHO definition for severe falciparum malaria is used [13].

\footnotetext{
* Correspondence: msnunes1@yahoo.com.br

${ }^{1}$ Health Sciences Centre, Federal University of Acre, BR 364 KM 04, Rio Branco, Acre, Brazil

Full list of author information is available at the end of the article
}

Vivax malaria is an important morbidity in children living in countries with endemic transmission. At the same time, children are also susceptible to other infections, such as viral diseases, because they still lack specific immunity to most of the pathogens in their first years of life, and co-morbidities can occur, especially in underdeveloped and developing regions, such as the Amazon.

This is the report of a case of acute myocarditis and dilated cardiomyopathy associated with cytomegalovirus (CMV) infection and vivax malaria in an infant residing in the Brazilian Amazon region.

\section{Case report}

A 13-month old girl living in the rural area of Cruzeiro do Sul, in Acre state (a small town of 73,000 inhabitants that notified 16,500 malaria cases in 2012) was admitted to a local hospital facility on September $9^{\text {th }}, 2013$ with a complaint of shortness of breath for approximately 30 days prior to the admission. Her parents referred to productive cough and fever in the preceding days. Her 
medical history (referred by parents) included a threeday hospital admission at the age of 11 months (June 2013) for respiratory symptoms, which were considered to be 'pneumonia', according to parents report. Since she had fever and lived in an area of malaria transmission, she was tested for malaria. Malaria records showed that she was diagnosed with vivax malaria, confirmed by microscopy. Malaria treatment was initiated with oral chloroquine ( $25 \mathrm{mg} / \mathrm{kg}$ over three days) and primaquine $(0.5 \mathrm{mg} / \mathrm{kg} /$ day over seven days) while she was in the hospital, and primaquine treatment was completed later at home, according to parents' report. She had been born full-term, 3,695 kg in weight and $50 \mathrm{~cm}$ in length, from caesarean surgery. Her mother denied attending prenatal care during pregnancy.

At hospital admission, she had signs of respiratory distress on physical examination, with wheezing, crackles, and nasal flare. Heart rate was $129 \mathrm{bpm}$, respiratory rate was $26 \mathrm{ipm}$. She measured $72 \mathrm{~cm}$ in length and her weight was $9 \mathrm{~kg}$. There was mild hepatomegaly. During the next three days, her heart rate escalated to $162 \mathrm{bpm}$, respiratory frequency varied between 26 and $50 \mathrm{bpm}$, and axillary temperature ranged from 37 to $37.8^{\circ} \mathrm{C}$. Based on signs of respiratory distress and productive cough, there was an initial diagnosis of pneumonia and she was started on ceftriaxone on the day of admission.
The electrocardiogram showed sinus rhythm, left ventricular overload and left atrial overload (Figure 1). Chest $\mathrm{X}$-ray showed pulmonary congestion and enlarged cardiac area (Figure 2). A thick smear for malaria diagnosis was negative on September $11^{\text {th }}$. According to the protocol stipulated by the Ministry of Health, 100 high power fields were examined before a negative diagnosis was issued. Unfortunately, rapid diagnostic tests for malaria were not available at the hospital at this time.

Because of her critical conditions, she was referred to a larger hospital in another city (Rio Branco) on September $13^{\text {rd }}$, with a diagnosis of cardiac failure of unknown origin, where she was seen by a paediatric cardiologist. On examination, she had severe dyspnoea $(50 \mathrm{ipm})$ and a regular tachycardic heartbeat (140 bpm), with hypophonetic heart sounds. The first echocardiogram, performed on September $14^{\text {th }}$, showed dilated cardiomyopathy with severe systolic dysfunction: mildly dilated left atrium $(27.2 \mathrm{~mm})$, severely dilated left ventricle $(60 \times 50 \mathrm{~mm})$, ejection fraction of $35 \%$, severe mitral insufficiency, mild aortic valve insufficiency, and no signs of cardiac malformation. Laboratory examinations showed normal erythrocyte sedimentation rate, negative C-reactive protein test, normal CPK (26 U/l, range 26-155 U/l), increased value of CK-mB (42 U/l, normal: less than $25 \mathrm{U} / \mathrm{L}$ ), AST $42 \mathrm{U} / \mathrm{l}$, ALT $21 \mathrm{U} / \mathrm{l}$. A haemogram revealed anaemia (haemoglobin

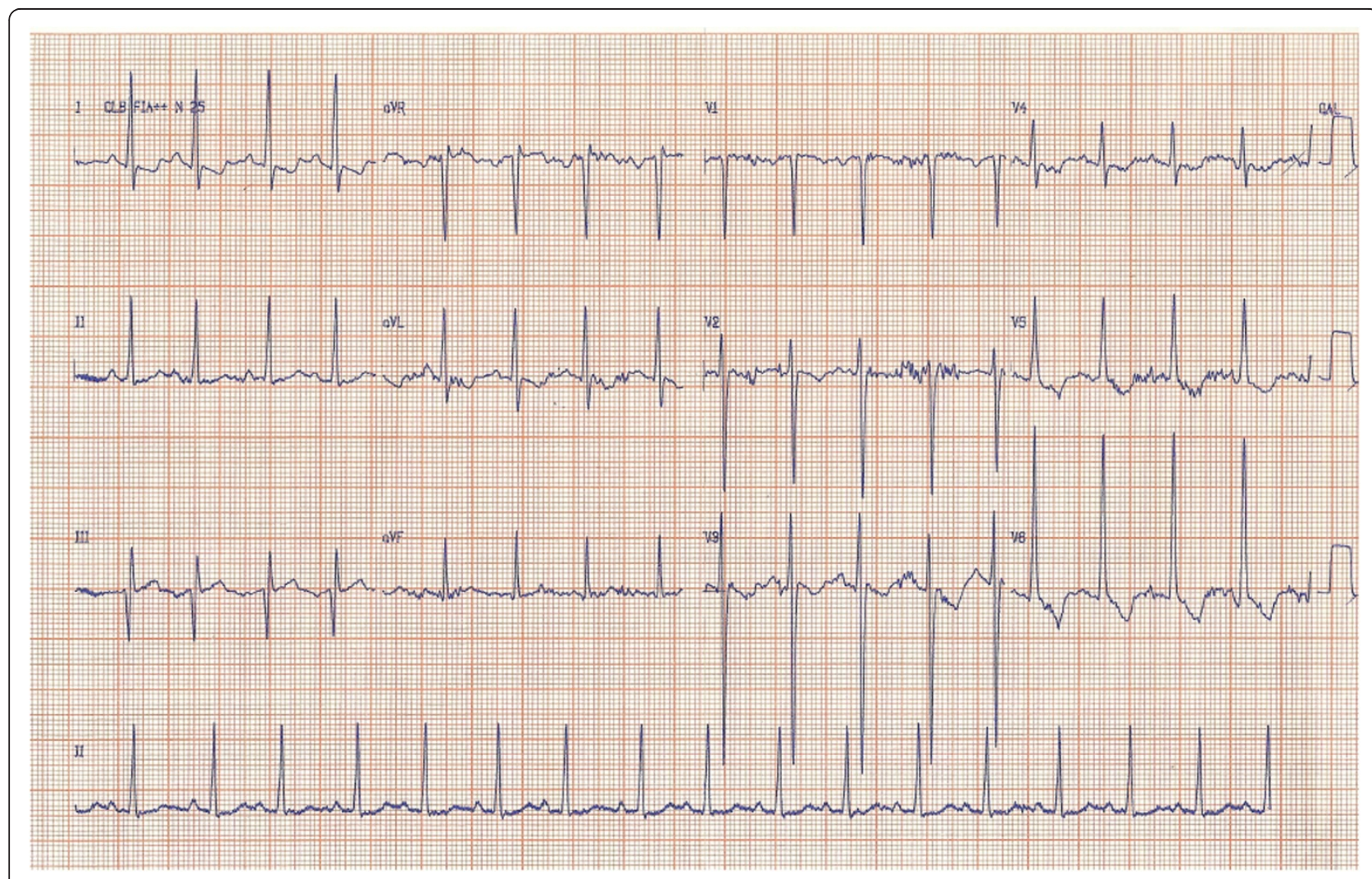

Figure 1 Electrocardiogram in a child with dilated cardiomyopathy. The electrocardiogram shows left ventricular and atrial overload. 


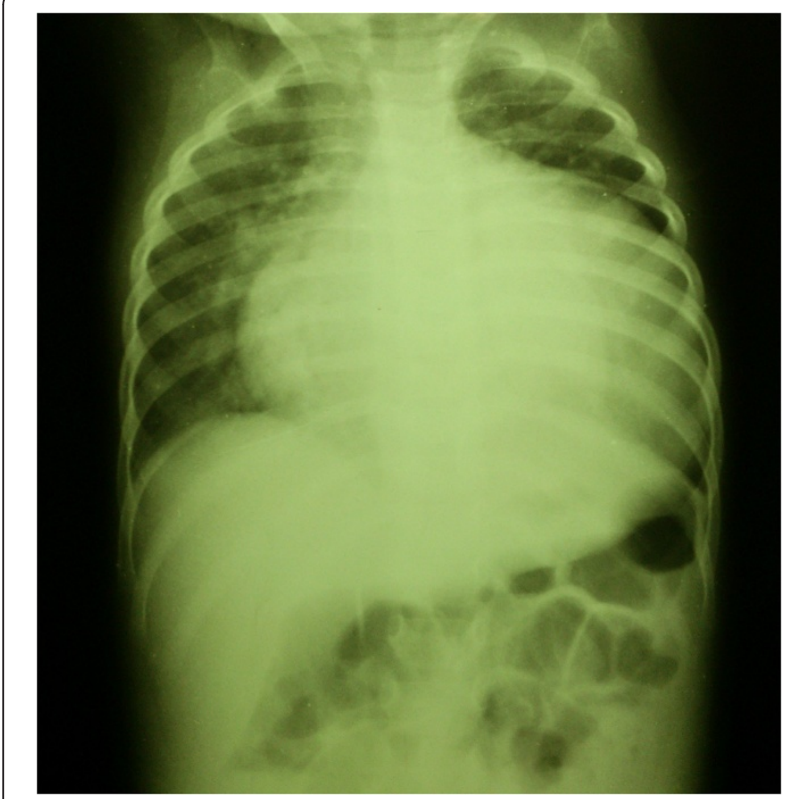

Figure $\mathbf{2}$ Chest radiography showing cardiomegaly. There is marked dilation of the left ventricle and increased pulmonary blood flow.

$9.69 \mathrm{~g} / \mathrm{dL})$ and mild leukocytosis $\left(10,900\right.$ cells $\left./ \mathrm{mm}^{3}\right)$, with $57 \%$ of granulocytes and $46 \%$ of lymphocytes, with normal platelet count $\left(370,000 / \mathrm{mm}^{3}\right)$. Another blood thick smear for malaria was performed on September $13^{\text {rd }}$, using the same criteria described before, which was also considered to be negative. She continued to receive ceftriaxone, and she was started on carvedilol, digoxin, furosemide, captopril, spironolactone, and oxacilin.

Between September $13^{\text {rd }}$ and $17^{\text {th }}$ she remained in stable condition with gradual decrease of heart rate (from 130 to $100 \mathrm{bpm}$ ) and respiratory rate (from 50 to $28 \mathrm{ipm})$. There was also disappearance of other clinical signs of respiratory distress.

On September $17^{\text {th }}$, she had diarrhoea with liquid stools which lasted nine days, with up to seven evacuations per day, accompanied by low-grade fever $\left(37.2-37.6^{\circ} \mathrm{C}\right)$. On 19 September, the CKmB levels returned to normal (19.20 $\mathrm{U} / \mathrm{l})$. Ceftriaxone was terminated on September $20^{\text {th }}$ but the patient continued to present low-grade fever in the next days.

Ceftazidime and vancomycin were started on September $23^{\text {rd }}$, because fever did not cease and clinical conditions were getting worse day by day even after a full course of Ceftriaxone, making the clinicians very worrisome about her clinical status Diarrhoea ceased after three days of vancomycin, but axillary temperature continued to raise and reached $38.5^{\circ} \mathrm{C}$ despite antibiotic administration. On September $29^{\text {th }}$, she was started on dipirone every six hours; haemoglobin values were $8.3 \mathrm{~g} / \mathrm{dL}$. OnOctober $3^{\text {rd }}$ haemoglobin values had decreased to $6.6 \mathrm{~g} / \mathrm{dL}$, when she received a blood transfusion because of the acute drop in haemoglobin levels. There was worsening of dyspnoea (from 30 to $42 \mathrm{ipm}$ ) and tachycardia (from 110 to $124 \mathrm{bpm}$ ), and on October $4^{\text {th }}$, another thick blood smear for malaria was performed, which was positive for $P$. vivax, with approximately 10,000 parasites $/ \mathrm{mm}^{3}$. Molecular diagnosis of Plasmodium species was performed using nested polymerase chain reaction $[14,15]$, and it confirmed a mono-infection by P. vivax (Figure 3). Glucose levels were $74 \mathrm{mg} / \mathrm{dL}$ at this point. Standardized treatment with chloroquine $(25 \mathrm{mg} / \mathrm{kg}$ over three days) and primaquine $(0.5 \mathrm{mg} / \mathrm{kg} /$ day over seven days) according to Brazilian Ministry of Health [16] was started. After

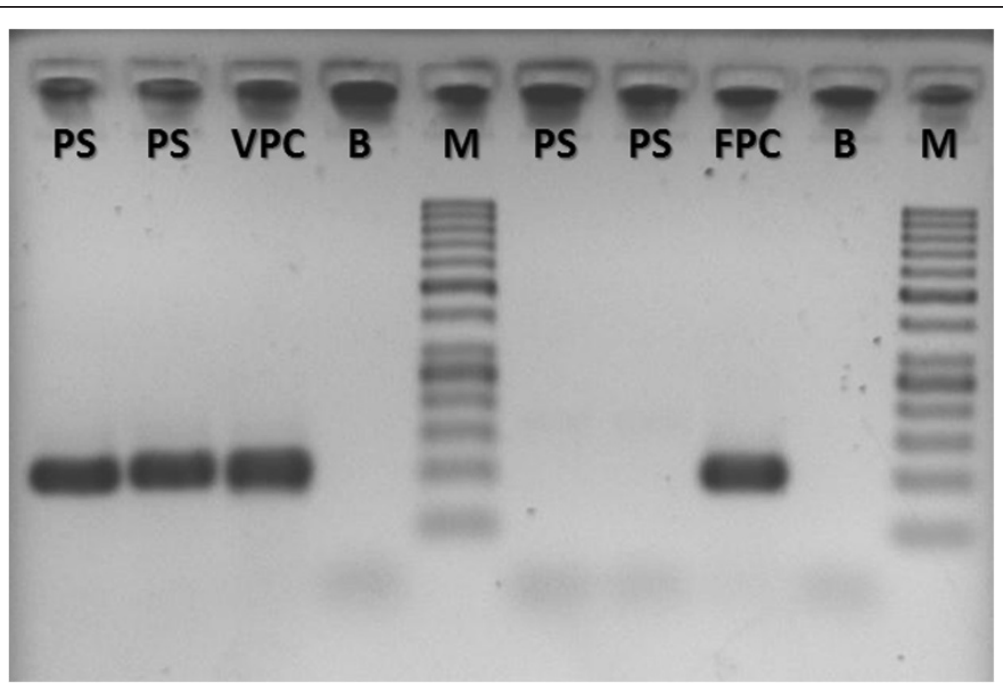

Figure 3 Molecular diagnosis of Plasmodium vivax infection. A DNA sample of the patient was submitted to nested PCR and it was positive for $P$. vivax mono-infection. $P S=$ Patient sample; $V P C=P$. vivax positive control; $F P C=P$. falciparum positive control; $B=B$ lank; $M=M o l e c u l a r$ weight marker. 
transfusion, haemoglobin levels reached $9.5 \mathrm{~g} / \mathrm{dL}$. However, a day later haemoglobin had decreased again to $7.7 \mathrm{~g} / \mathrm{dL}$ and platelet count was $47,000 / \mathrm{mm}^{3}$. The patient was clinically anicteric, but no laboratory measurement of bilirubin was performed. Table 1 shows the result of haemograms and Figure 4 shows the relationship between fever, haemoglobin levels and platelet counts. After malaria diagnosis, the patient started to receive hourly antipyretics.

A panel of serologic tests for the most common infectious agents known to cause myocarditis in children was performed. Anti-CMV antibodies were detected on October $4^{\text {th }}$ (IgM of 2.66 for a cut-off $>=1.0$ and IgG higher than 250, cut-off $>6.0$ ), and six days later, IgM titres increased to 9.34 (cut-off $>=1.0$ ). Laboratory investigation for other infectious agents (hepatitis B, hepatitis C, HIV, Epstein Barr virus, Toxoplasma gondii, Trypanosoma cruzi) were negative on two separate samples (October $4^{\text {th }}$ and October $10^{\text {th }}$ ). It was decided not to use gancyclovir because there was no evidence of possible clinical benefit at this point and since this drug can cause bone marrow toxicity, it may have exacerbated the anaemia and thrombocytopaenia if it had been used [18].

Fever resolved on day 3 of chloroquine + primaquine treatment (October $6^{\text {th }}$ ) and dyspnoea improved from $7^{\text {th }}$ October onwards. There was a progressive significant clinical improvement with disappearance of respiratory distress between October $7^{\text {th }}$ and $14^{\text {th }}$. Despite this clinical improvement, cardiac echocardiogram remained mostly unchanged. A second echocardiogram performed on October $1^{\text {st }}$ showed dilated cardiomyopathy with severe systolic dysfunction, increased dilation of left atrium $(31.9 \mathrm{~cm})$, severe distension of left ventricle $(48 \mathrm{~cm} \times$ $39.5 \mathrm{~cm}$ ), ejection fraction of $36 \%$ and severe mitral valve insufficiency. CMV IgM was 1.44 on October $25^{\text {th }}$. The third echocardiogram performed on November 1st showed severe dilation of left atrium $(31 \mathrm{~mm}, \mathrm{Z}$ score + $4.35)$, severe dilation of left ventricle $(54 \mathrm{~mm}, \mathrm{Z}$ score + 9.43), moderate mitral valve insufficiency secondary to ventricle dilation, severe systolic dysfunction with an ejection fraction of $41 \%$ and myocardial performance index of 1.03 (defined as the sum of isovolumetric contraction and relaxation time divided by the ejection time) (Figures 5 and 6). She continued to improve clinically and remained without clinical signs of respiratory distress despite maintaining cardiac dysfunction, and was kept on close treatment follow-up with prescription of furosemide, captopril, spironolactone, digoxin, and carvedilol. Figure 7 illustrates the most important events of the case.

\section{Discussion}

The main features of this case are the dilated cardiomyopathy associated with respiratory distress and vivax malaria that presents later on the course of the disease. The cause of the dilated cardiomyopathy is problably CMV-induced myocarditis. Myocarditis can be acute, subacute or chronic, and it is characterized by a variety of symptoms, ranging from mild chest pain to cardiac shock and sudden death. In children, the most common symptoms are dyspnoea, vomiting, fever, and lethargy. Most of paediatric myocarditis is not recognized at the beginning, making the diagnosis even more difficult.

Table 1 Haemoglobin levels, leukocyte and differential counts, and platelet counts between initial admission on 10 September and malaria treatment in early October, 2013

\begin{tabular}{|c|c|c|c|c|c|c|}
\hline & $\begin{array}{l}\text { Haemoglobin } \\
(\mathrm{mmol} / \mathrm{l})\end{array}$ & Leukocytes $\left(\mathrm{mm}^{3}\right)$ & $\begin{array}{c}\text { Segmented } \\
\text { neutrophils \% }\end{array}$ & Lymphocytes \% & Platelets $\left(* 10^{9} / \mathrm{I}\right)$ & $\begin{array}{c}\text { Important } \\
\text { clinical events }\end{array}$ \\
\hline $10 / 9$ & 9.7 & 13,800 & 32 & 57 & 366 & $\begin{array}{l}\text { Dyspnoea, } \\
\text { starts Ceftriaxone }\end{array}$ \\
\hline $12 / 9$ & 9.7 & 7,900 & 45 & 49 & 292 & \\
\hline $13 / 9$ & 9.69 & 10,900 & 57 & 41 & 388 & \\
\hline $13 / 9$ & 10 & 14,900 & 48 & 46 & 370 & \\
\hline $15 / 9$ & 9.7 & 10,600 & 31 & 54 & 311 & \\
\hline $23 / 9$ & 9.5 & 32,200 & 70 & 16 & 299 & $\begin{array}{c}\text { Diarrhoea since 17/9; } \\
\text { starts Ceftazidime + Vancomycin }\end{array}$ \\
\hline $26 / 9$ & 9.5 & 9,500 & 53 & 36 & 320 & \\
\hline $27 / 9$ & 9.7 & 8,400 & 42 & 46 & 224 & Fever $38.5^{\circ} \mathrm{C}$ \\
\hline $29 / 9$ & 8.3 & 9,200 & 56 & 38 & 300 & \\
\hline $3 / 10$ & 6.6 & 12,100 & 53 & 13 & 102 & Blood transfusion after haemogram \\
\hline $4 / 10$ & 9.5 & 9,600 & 49 & 38 & 361 & Smear positive for $P$. vivax \\
\hline $5 / 10$ & 7.4 & 7,400 & 33 & 48 & 47 & \\
\hline $6 / 10$ & 7.7 & 14,800 & 32 & 48 & 79 & \\
\hline
\end{tabular}

Reference values for 6 months to 2 years old children: 10.5 to $13.5 \mathrm{~g} / \mathrm{dL}$ haemoglobin, $6,000-17,500$ leucocytes/ $\mu \mathrm{L}$, $15-35 \%$ segmented neutrophils, 45 - $6775 \%$ lymphocytes [17]. 


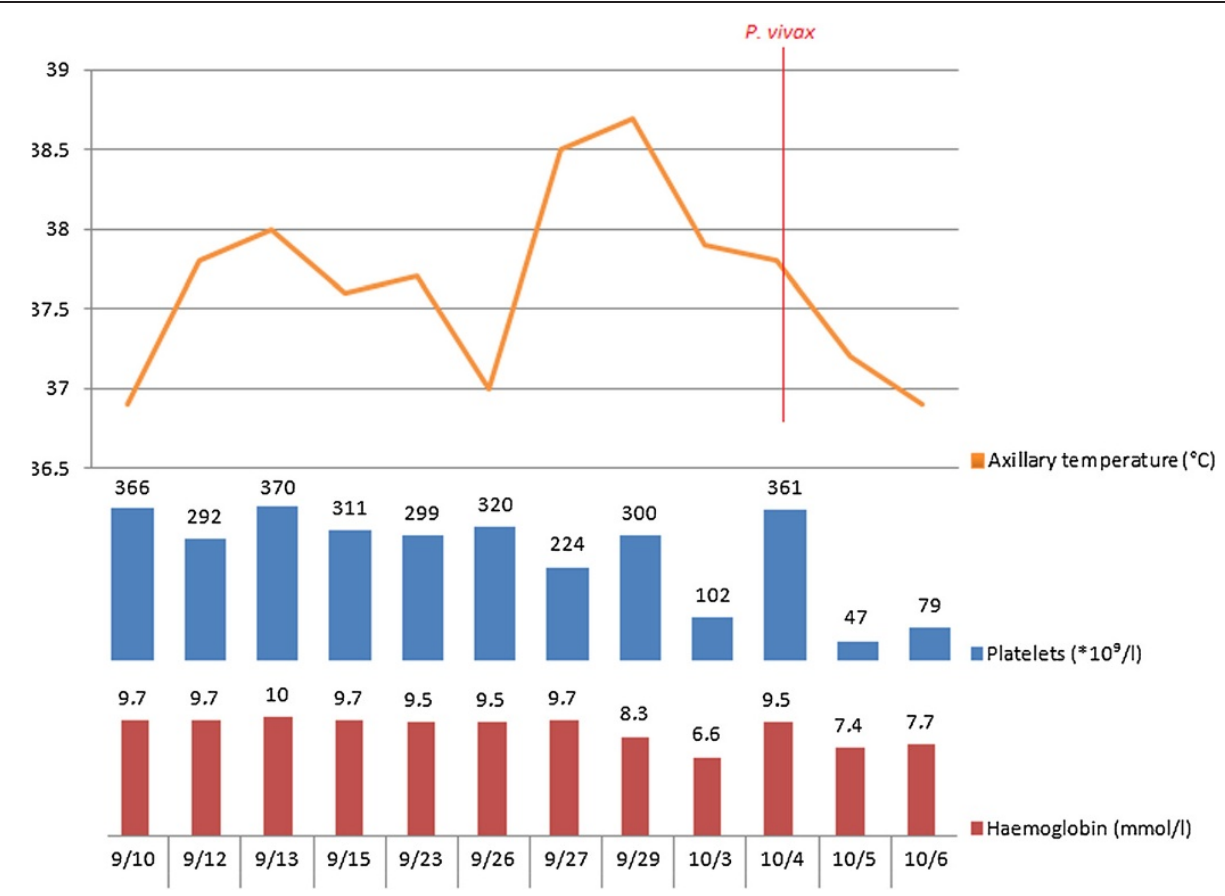

Figure 4 Clinical evolution of fever, platelet counts and haemoglobin and its relation with malaria. On admission (10/9) haemogobin level was $9.7 \mathrm{mmol} / \mathrm{l}$ and platelet count was normal. After a few days of admission axillary temperature increased, peaking on 29/9, when hourly antipyretics were prescribed. Four days later there was an acute drop on haemoglobin levels and platelet counts. The patient received a blood transfusion on 3/10, resulting in increased platelet count and haemoglobin levels. However, they declined again on 5/10. A positive smear for P. vivax was obtained in $4 / 10$.

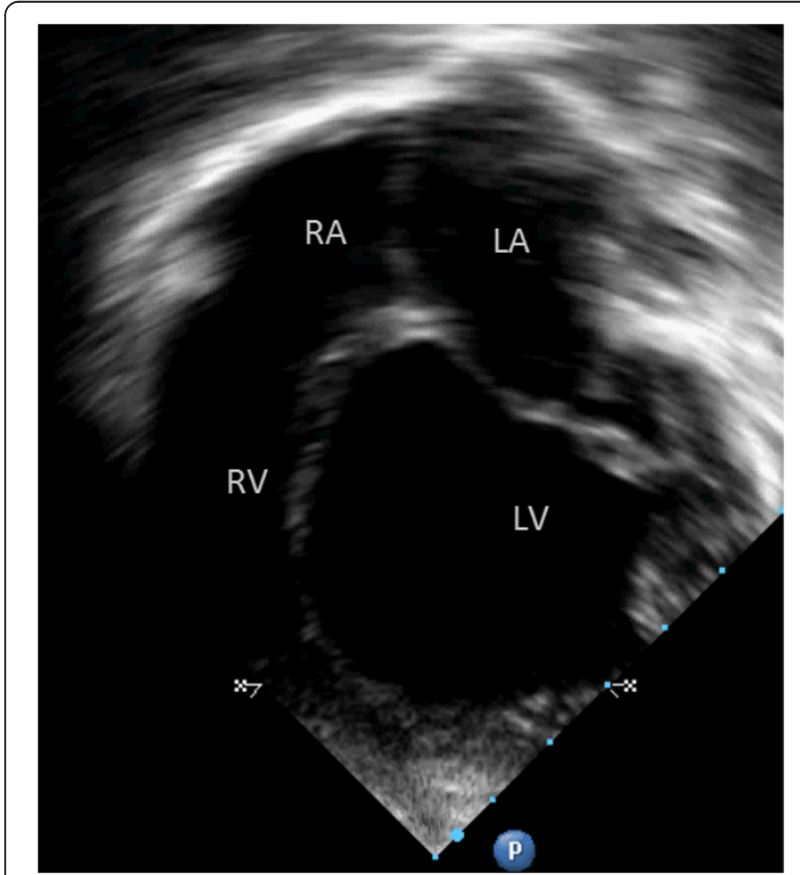

Figure 5 Four-chamber echocardiographic image showing marked dilation of the left ventricle. $R A=$ right atrium, $L A=l e f t$ atrium, $\mathrm{RV}=$ right ventricle, $\mathrm{LV}=$ Left ventricle.
Specific EKG change is increased PR interval, but ventricular and atrial overload are seen with the progression to dilated cardiomyopathy. In severe cases, cardiac insufficiency may develop because of acute severe injury or resulting dilated cardiomyopathy. In these cases, tachycardia, tachypnea and respiratory distress are frequent [19]. Although the gold standard examination for diagnosing myocarditis is myocardial biopsy, this procedure is not often performed. Ancillary diagnostic examinations include eletrocardiogram, echocardiogram and magnetic resonance of the heart [20]. Paediatric myocarditis are mostly caused by viral infections, namely enteroviruses (Coxsackie virus, echovirus and poliovirus). Other viruses are also associated with this lesion, such as parvovirus B 19, herpesvirus 6, influenza, para-influenza, adenovirus, Epstein Barr virus, and CMV. Less frequently, other nonviral agents, such as Toxoplasma gondii and Trypanosoma cruzi, can also cause acute myocarditis [21].

This child presented serial venous samples with increasing titres of seric IgM anti-CMV and high titres of IgG during admission. Studies on window interval with blood donors and blood recipients [22], and naturally infected immuno-competent patients [23] show that CMV genes are readily detectable while CMV-specific antibodies will take between three and five weeks after infection to be detected, supporting the hypothesis of CMV- 


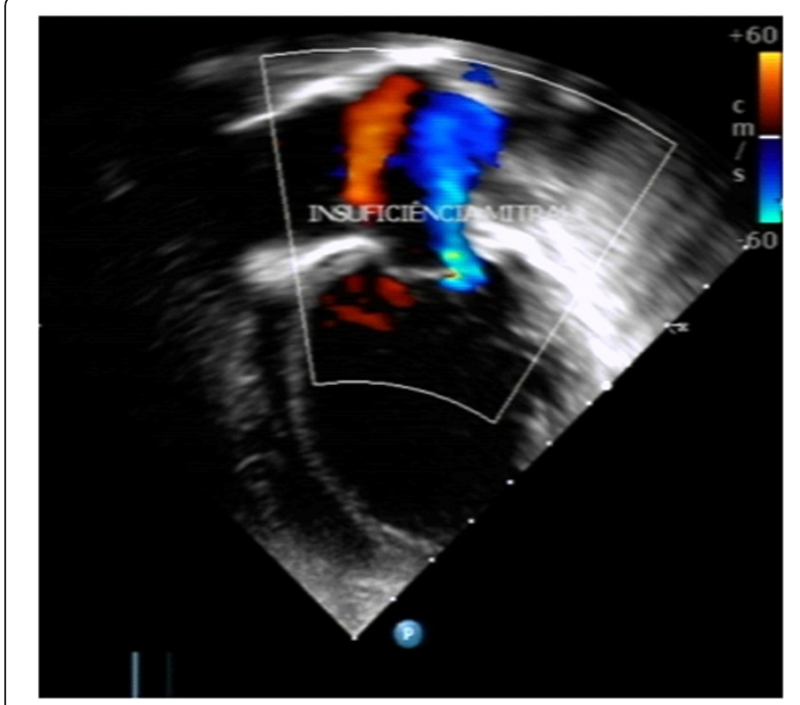

Figure 6 Echocardiographic image showing marked dilation of the left ventricle and mitral regurgitation (in blue) of moderate degree.

related myocardial lesion in this child. Other studies show that IgM can take up to eight weeks to be detectable [24].

Several authors have described CMV-induced myocarditis. Evidence of CMV infection in 'idiopathic' dilated cardiomyopathy has also been shown [23,25]. A case of dilated cardiomyopathy in a two-month old infant with congenital CMV infection shows that progression from myocarditis to cardiomyopathy can occur in a few months [26], and that CMV specific IgM antibodies can be detectable at least 16 weeks after myocarditis has occurred [26].
It is possible that in this patient, CMV infection and acute myocarditis started in June, at the time of her first hospital admission, and that it was misdiagnosed as pneumonia because of respiratory symptoms. It has been shown that CMV can simulate pneumonia because of pronounced pulmonary congestion [25]. As pulmonary congestion and other symptoms of cardiac insufficiency increased and she progressed to dilated cardiomyopathy, the diagnosis of cardiac injury was made and she was referred to a larger hospital where other examinations and a proper diagnosis could be made.

The evolution of acute myocarditis to dilated cardiomyopathy has been explained by the occurrence of inflammatory lesion to the myocardial cell and adverse remodelling resulting in dilated cardiac chambers $[27,28]$. Experimental studies suggest that CMV infects the myocardial cell, which are then attacked by macrophages and natural killer cells, and later on by $\mathrm{T}$ lymphocytes, around 15 and 30 days post-infection $[28,29]$. After that, there is progression to fibrosis, cavity enlargement and heart failure, between 30 and 90 days post-infection [28], with persistence of viral genome in the heart even after 90 days of infection [28]. Sakaguchi et al. [26] described a case of congenital infection in which impaired cardiac function was detected at 30 weeks of gestation already. In the present case report, the time between the first hospital admission with fever and respiratory symptoms, and the respiratory distress leading to the second hospital admission was between four to eight weeks, supporting the hypothesis that this was a case of CMV-induced myocarditis progressing to dilated cardiomyopathy.

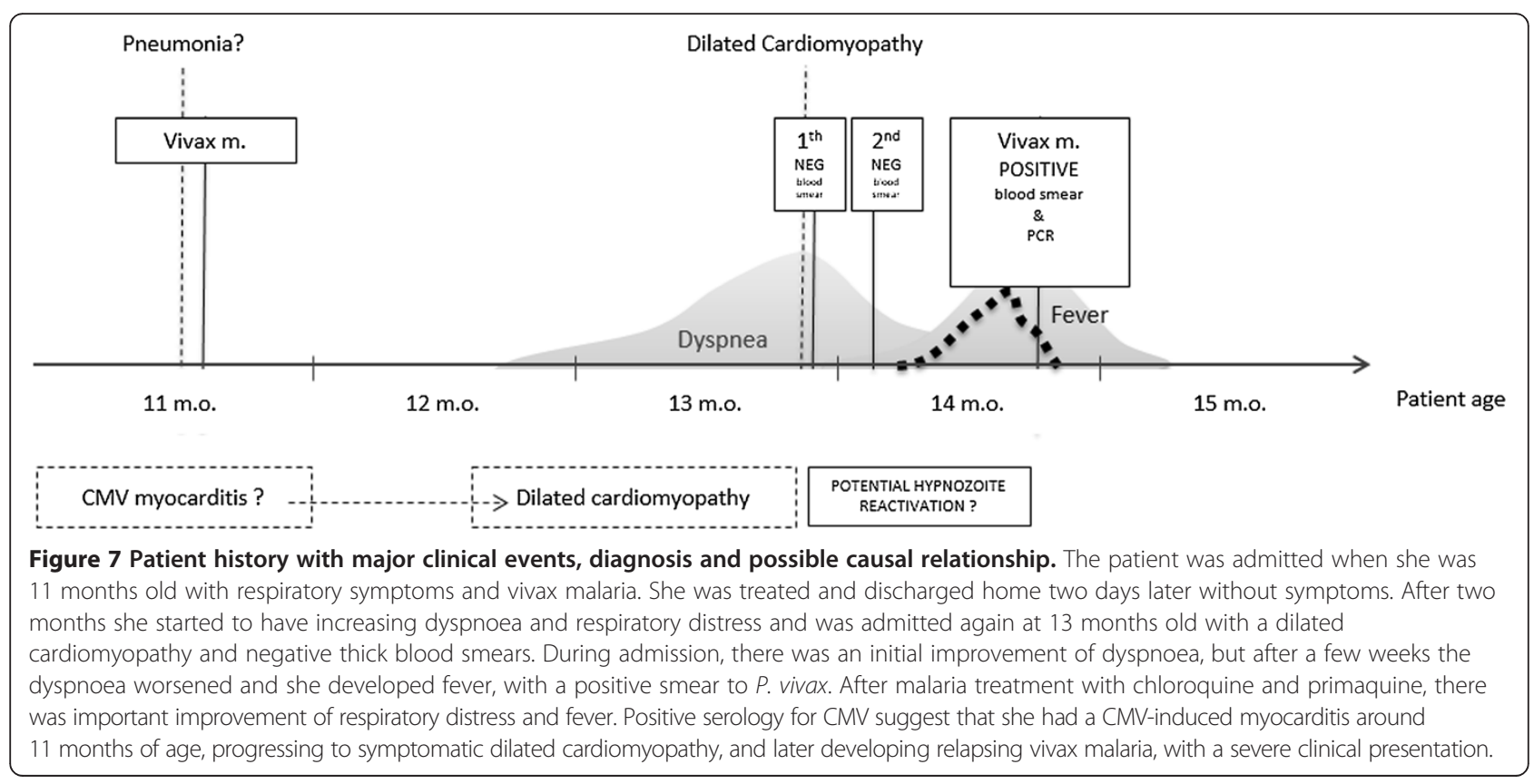


Besides having a pre-existing severe cardiac disease, this child also developed vivax malaria. Criteria for recognizing severe vivax malaria are now being discussed in the literature. Series of case reports and review of literature show a range of clinical and laboratory findings that are frequently seen in patients with severe vivax malaria $[10,11,30]$. These parameters included severe thrombocytopaenia [31,32], variable degrees of anaemia [5,33,34] (including severe anaemia with haemoglobin level $<5 \mathrm{~g} / \mathrm{dL}$ ), lung injury with respiratory distress (mainly in children) $[2,5,30,35,36]$, renal failure and jaundice [31,33,37], and less frequently, coma or cerebral malaria [2]. In this case, there was an acute drop in haemoglobin levels, together with worsening of respiratory symptoms. Although these changes do not meet the criteria currently used for severe malaria, the appearance of this second episode of vivax malaria contributed to worsening of clinical conditions.

In this case, the patient was already in respiratory distress, possibly as a result of CMV infection leading to dilated cardiomyopathy and pulmonary congestion, which worsened with the appearance of peripheral Plasmodium parasitaemia. Interestingly, treatment of malaria reduced the respiratory distress substantially, which confirms the role of Plasmodium in increasing the previous pulmonary injury she presented at admission. The mechanism of vivax-induced respiratory distress is currently attributed to cytoadherence to the lung microvasculature [38] and increased permeability of the alveolar-capillary membrane caused by sequestration and inflammatory response to the Plasmodium and its treatment [39], which is supported by post-mortem findings in Brazil [40]. On the other hand, malaria can also impairs cardiac function. Tachycardia, diminished ejection fraction and impaired left ventricular function were frequent in Kenyan children with severe falciparum malaria, and after treatment a significant improvement in cardiac function was observed. The aetiology of such cardiac depression is not clear, and may be related to cytokine release, acidosis, hypovolaemia or sequestration of red cells in myocardial vessels [41]. There are a few other reports of myocardial dysfunction caused primarily by malaria, all of them related to severe Plasmodium falciparum infection [42-44] and one caused by experimental malaria [45].

This one-year old child had a vivax malaria episode in June and another episode in October. Since she had a prolonged admission stay (23 days) with two negative thick blood smears and there is no malaria transmission in Rio Branco (where the hospital was located), it is highly possible that the patent parasitaemia detecting on 4 October, and the preceding seven days of fever, were the result of hypnozoite reactivation. Vivax malaria treatment was administered orally and it is possible that treatment with primaquine at home was not adequate in June, which would favour early relapse when facing a systemic disease [46]. It is less likely that recrudescence would occur, since chloroquine treatment was performed inside the hospital and most of recrudescence cases are seen within a month after incomplete treatment.There is scarce data on vivax relapses in the Brazilian Amazon. In 1991, Boulos et al. [47] estimated a 7\% rate of relapsing vivax episodes, occurring up to 90 days after the first episode. There are no other recent reports for data comparison. Since albeit had not been possible to do rapid diagnostic tests or molecular testing for malaria before October $4^{\text {th }}$, it is conceivable that she had a very low $P$. vivax parasitaemia that was missed at hospital admission, but even in this situation, a relapsing malaria would be feasible due to improper treatment in June. In Brazil, access to anti-malarials is controlled by the Ministry of Health, and chloroquine usage is only allowed in two very defined situations: following a positive diagnostic test or as prophylaxis for recurrent vivax malaria after the second episode when primaquine cannot be used (children under 6 months of age and pregnant women) [16].

It is described that repeated episodes of malaria can cause the removal of both infected and uninfected red blood cells, which could explain the anaemia observed at the second hospital admission, together with some degree of iron deficiency caused by low intake. The substantial drop of haemoglobin levels around October $4^{\text {th }}$, on the other hand, is directly related to the severity of vivax malaria [30], and can be caused by haemolysis, impaired haemopoiesis or spleen sequestration. This child also presented lymphopaenia, detected in October $3^{\text {rd }}$, one day before she had a positive thick smear form malaria. Although it is not a correlate of severe disease, lymphopaenia is frequent in malaria patients [48].

The aetiology of diarrhoea was not formally investigated, but it is possible that she had an antibiotics-associated colitis, or even Clostridium difficile-associated diarrhoea. Clostridium difficile diarrhoea is the most common cause of diarrhoea associated with antibiotic usage, and the most common symptoms in children are liquid stools that resolve in 30 days, while adults tend to have pseudomembranous colitis much more frequently [49]. This child was started empirically on vancomycin and diarrhoea resolved three days later, while fever continued to exist. Changes in haemogram from September $23^{\text {rd }}$ showed increased leucocyte count with increased segmented neutrophils, supporting the hypothesis of an antibiotic-associated $C$. difficile diarrhoea [49].

Technical limitations that are common in the Amazonian health care system prevented a more detailed investigation of the case. Malaria smears should have been performed earlier and more often during the course of admission in this case, and maybe this would have prevented the acute drops in haemoglobin levels and platelet numbers, and the worsening of cardiorespiratory function. The aetiology 
of diarrhoea was not properly investigated either. Social conditions will make the follow-up of this child with cardiac insufficiency more difficult, since at her home area there is no cardiologic health care available. It is worth pointing out that in malaria-endemic settings, socio-economic inequalities can facilitate the occurrence of co-morbidities and at the same time may hinder proper health care.

\section{Conclusion}

This case portrays the concomitance of two important infectious diseases in a young child. While CMV infection is a cosmopolitan infectious agent, vivax malaria is a disease associated with social inequities, and should be investigated in all patients with similar settings. Health care provided to this patient at the beginning of clinical course was limited because of inherent health care access in the Amazon, but despite that, medical efforts were able to keep her health condition stable.

\section{Consent}

Written informed consent was obtained from the parents of the patient for publication of this case report and any accompanying images. A copy of the written consent is available for review by the Editor-in-Chief of this journal.

\section{Competing interests}

The authors declare they have no competing interests.

\section{Authors' contributions}

ACM, JBL, LMNS, and TCM provided clinical care to the patient and pursued the initial clinical investigation, interpretation of exams and malaria diagnosis. LNF and RSM carried out the molecular diagnosis of Plasmodium infection. MCVR and RBR performed the cardiological evaluation and diagnosis and provided final health care to the patient. MdaSN participated as an infectious disease consultant expert. ACM and MdaSN conceived the case report, participated in its design and coordination and wrote the manuscript. MCVR and RBR helped to draft the manuscript. JBL, LMNS, TCM, LNF, and RSM revised the manuscript critically for important intellectual and clinical content. All authors approved the final manuscript.

\section{Acknowledgements}

The authors thank Livia Rocha, from University of Sao Paulo, for preparing patient samples for molecular diagnosis of malaria, and the parents of the child, who allowed us to publish this clinical history and contribute to increase the medical knowledge.

\section{Author details}

${ }^{1}$ Health Sciences Centre, Federal University of Acre, BR 364 KM 04, Rio Branco, Acre, Brazil. 'Pediatrics, Children's Hospital, Rio Branco, Acre, Brazil.

${ }^{3}$ Tropical Medicine Institute, University of São Paulo, São Paulo, Brazil.

Received: 4 December 2013 Accepted: 14 February 2014

Published: 18 February 2014

\section{References}

1. Sharma S, Aggarwal KC, Deswal S, Raut D, Roy N, Kapoor R: The unusual presentation of a usual organism - the changing spectrum of the clinical manifestations of Plasmodium vivax malaria in children: a retrospective study. J Clin Diagn Res 2013, 7:1964-1967.

2. Gehlawat VK, Arya V, Kaushik JS, Gathwala G: Clinical spectrum and treatment outcome of severe malaria caused by Plasmodium vivax in 18 children from northern India. Pathog Glob Health 2013, 107:210-214.
3. Tanwar GS, Lahoti A, Tanwar P, Agrawal R, Khatri PC, Kochar DK: Hemophagocytic syndrome associated with severe Plasmodium vivax malaria in a child in Bikaner (northwestern India). J Vector Borne Dis 2013, 50:318-320.

4. Rizvi I, Tripathi DK, Chughtai AM, Beg M, Zaman S, Zaidi N: Complications associated with Plasmodium vivax malaria: a retrospective study from a tertiary care hospital based in Western Uttar Pradesh, India. Ann Afr Med 2013, 12:155-159.

5. Ketema T, Bacha K: Plasmodium vivax associated severe malaria complications among children in some malaria endemic areas of Ethiopia. BMC Public Health 2013, 13:637.

6. Abdallah TM, Abdeen MT, Ahmed IS, Hamdan HZ, Magzoub M, Adam I: Severe Plasmodium falciparum and Plasmodium vivax malaria among adults at Kassala Hospital, eastern Sudan. Malar J 2013, 12:148.

7. Lon C, Timmermans A, Buathong N, Nou S, Se Y, Sitthy N, Chann S, Kraesub S, Wongstitwilairoong T, Walsh DS, Tyner S, Fukuda M, Callender D, Sherwood t, Koy L, Char M, Bethell D, Saunders D: Severe malaria in Battambang Referral Hospital, an area of multidrug resistance in Western-Cambodia: a retrospective analysis of cases from 2006-2009. Malar J 2013, 12:217.

8. Pinzón MA, Pineda JC, Rosso F, Shinchi M, Bonilla-Abadía F: Plasmodium vivax cerebral malaria complicated with venous sinus thrombosis in Colombia. Asian Pac J Trop Med 2013, 6:413-415.

9. Siqueira AM, Alexandre MA, Mourão MP, Santos VS, Nagahashi-Marie SK, Alecrim MG, Lacerda MV: Severe rhabdomyolysis caused by Plasmodium vivax malaria in the Brazilian Amazon. Am J Trop Med Hyg 2010, 83:271-273.

10. Alexandre MA, Ferreira CO, Siqueira AM, Magalhães BL, Mourão MP, Lacerda MV, Alecrim M: Severe Plasmodium vivax malaria, Brazilian Amazon. Emerg Infect Dis 2010, 16:1611-1614.

11. Lança EF, Magalhães BM, Vitor-Silva S, Siqueira AM, Benzecry SG, Alexandre MA, O'Brien C, Bassat Q, Lacerda MV: Risk factors and characterization of Plasmodium vivax-associated admissions to pediatric intensive care units in the Brazilian Amazon. PLoS One 2012, 7:e35406.

12. Raposo CC, Santos JB, Santos GM, Gonçalves Eda G, Silva AR: Plasmodium vivax malaria: related factors to severity in the State of Maranhão, Brazil. Rev Soc Bras Med Trop 2013, 46:67-72.

13. World Health Organization: Severe falciparum malaria. Trans Royal Soc Trop Med Hygiene 2000, 94:S1-S83.

14. Kimura M, Kaneko O, Liu Q, Zhou M, Kawamoto F, Wataya Y, Otani S, Yamaguchi $Y$, Tanabe K: Identification of the four species of human malaria parasites by nested PCR that targets variant sequences in the small subunit rRNA gene. Parasitol Int 1997, 46:91-95.

15. Win TT, Lin K, Mizuno S, Zhou M, Liu Q, Ferreira MU, Tantular IS, Kojima S, Ishii A, Kawamoto F: Wide distribution of Plasmodium ovale in Myanmar. Trop Med Int Health 2002, 7:231-239.

16. Brasil. Ministério da Saúde. Secretaria de Vigilância em Saúde. Departamento de Vigilância Epidemiológica: Guia pratico de tratamento da malaria no Brasil. Brasília : Ministério da Saúde: Ministério da Saúde, Secretaria de Vigilância em Saúde, Departamento de Vigilância Epidemiológica; 2010:36.

17. Proytcheva MA: Hematologic values in the healthy fetus, neonate, and child. In Diagnostic Pediatric Hematopathology. Edited by Proytcheva MA. Cambridge: Cambridge University Press; 2011:5-20.

18. Jacobsen $\mathrm{T}$, Sifontis $\mathrm{N}$ : Drug interactions and toxicities associated with the antiviral management of cytomegalovirus infection. Am J Health Syst Pharm 2010, 67:1417-1425. doi:10.2146/ajhp090424.

19. Durani $Y$, Giordano K, Goudie BW: Myocarditis and pericarditis in children. Pediatr Clin North Am 2010, 57:1281-1303.

20. Durani Y, Egan M, Baffa J, Selbst SM, Nager AL: Pediatric myocarditis: presenting clinical characteristics. Am J Emerg Med 2009, 27:942-947.

21. Kühl U, Schultheiss HP: Myocarditis in children. Heart Fail Clin 2010, 6:483-496.

22. Rafailidis PI, Mourtzoukou EG, Varbobitis IC, Falagas ME: Severe cytomegalovirus infection in apparently immunocompetent patients: a systematic review. Virol J 2008, 5:47.

23. Ziemann M, Heuft HG, Frank K, Kraas S, Görg S, Hennig: Window period donations during primary cytomegalovirus infection and risk of transfusion-transmitted infections. Transfusion 2013, 53:1088-1094.

24. Kusne S, Shapiro R, Fung J: Prevention and treatment of cytomegalovius infeciton in organ transplant recipients. Transp/ Infect Dis 1999, 1:187.203.

25. Dettmeyer R, Sperhake JP, Müller J, Madea B: Cytomegalovirus-induced pneumonia and myocarditis in three cases of suspected sudden infant death syndrome (SIDS): Diagnosis by immunohistochemical techniques and molecular pathologic methods). Forensic Sci Int 2008, 174:229-233. 
26. Sakaguchi H, Yamamoto T, Ono S, Akashi A, Tsuda E, Watanabe K: An infant case of dilated cardiomyopathy associated with congenital cytomegalovirus infection. Pediatr Cardiol 2012, 33:824-826.

27. Mason JW: Myocarditis and dilated cardiomyopathy: an inflammatory link. Cardiovasc Res 2003, 60:5-10

28. Kawai C: From myocarditis to cardiomyopathy: mechanisms of inflammation and cell death: learning from the past for the future. Circulation 1999, 99:1091-1100.

29. Cihakova D, Rose NR: Pathogenesis of myocarditis and dilated cardiomyopathy. Adv Immunol 2008, 99:95-114.

30. Price RN, Douglas NM, Anstey NM: New developments in Plasmodium vivax malaria: severe disease and the rise of chloroquine resistance. Curr Opin Infect Dis 2009, 5:430-435.

31. Bhattacharjee P, Dubey S, Gupta VK, Agarwal P, Mahato MP: The clinicopathologic manifestations of Plasmodium vivax malaria in children: a growing menace. J Clin Diagn Res 2013, 7:861-867.

32. Nadkar MY, Huchche AM, Singh R, Pazare AR: Clinical profile of severe Plasmodium vivax malaria in a tertiary care centre in Mumbai from June 2010-January 2011. J Assoc Physicians India 2012, 60:11-13.

33. Barcus MJ, Basri H, Picarima H, Manyakori C, Sekartuti, Elyazar I, Bangs MJ, Maguire JD, Baird JK: Demographic risk factors for severe and fatal vivax and falciparum malaria among hospital admissions in northeastern Indonesian Papua. Am J Trop Med Hyg 2007, 77:984-991.

34. Tjitra E, Anstey NM, Sugiarto P, Warikar N, Kenangalem E, Karyana M, Lampah DA, Price RN: Multidrug-resistant Plasmodium vivax associated with severe and fatal malaria: a prospective study in Papua, Indonesia. PLoS Med 2008, 5:e128.

35. Genton B, D'Acremont V, Rare L, Baea K, Reeder JC, Alpers MP, Müller I: Plasmodium vivax and mixed infections are associated with severe malaria in children: a prospective cohort study from Papua New Guinea. PLoS Med 2008, 5:e127.

36. Rahman AK, Sulaiman FN: Plasmodium vivax presenting as acute respiratory distress syndrome: case report. Trop Doct 2013, 43:83-85

37. Kochar DK, Das A, Kochar SK, Saxena V, Sirohi P, Garg S, Kochar A, Khatri MP, Gupta V: Severe Plasmodium vivax malaria: a report on serial cases from Bikanerin northwestern India. Am J Trop Med Hyg 2009, 80:194-198.

38. De Las SB, Segura C, Pabón A, Lopes SC, Costa FT, Blair S: Adherence to human lung microvascular endothelial cells (HMVEC-L) of Plasmodium vivax isolates from Colombia. Malar J 2013, 12:347.

39. Anstey NM, Handojo T, Pain MC, Kenangalem E, Tjitra E, Price RN, Maguire GP. Lung injury in vivax malaria: pathophysiological evidence for pulmonary vascular sequestration and posttreatment alveolar-capillary inflammation. J Infect Dis 2007, 195:589-596.

40. Costa FT, Lopes SC, Albrecht L, Ataíde R, Siqueira AM, Souza RM, Russell B, Renia L, Marinho CR, Lacerda MV: On the pathogenesis of Plasmodium vivax malaria: perspectives from the Brazilian field. Int J Parasitol 2012, 42:1099-1105.

41. Yacoub S, Lang HJ, Shebbe M, Timbwa M, Ohuma E, Tulloh R, Maitland K: Cardiac function and hemodynamics in Kenyan children with severe malaria. Crit Care Med 2010, 38:940-945

42. Kumar PP, Kumar CD, Shaik FA, Ghanta SB: Myocardial dysfunction in severe Falciparum malaria. J Trop Pediatr 2010, 56:67-68.

43. Mohsen AH, Green ST, West JN, McKendrick MW: Myocarditis associated with Plasmodium falciparum malaria: a case report and a review of the literature. J Travel Med 2001, 8:219-220.

44. Bhat S, Kumar M, Alva J: Malaria and the conducting system of the heart. BMJ Case Rep 2013. published online 29 January 2013, doi:10.1136/bcr-2012-007462.

45. Nieman AE, de Mast Q, Roestenberg M, Wiersma J, Pop G, Stalenhoef A, Druilhe $P$, Sauerwein $R$, van der Ven A: Cardiac complication after experimental human malaria infection: a case report. Malar J 2009, 8:277.

46. White NJ: Determinants of relapse periodicity in Plasmodium vivax malaria. Malar J 2011, 10:297.

47. Boulos M, Amato Neto V, Dutra AP, Di Santi SSM, Shiroma M: Analise da frequência de recaídas de malária por Plasmodium vivax em região não endêmica (São Paulo, Brasil). Rev Inst Med trop São Paulo 1991, 33:143-146.

48. Van Wolfswinkel ME, Vliegenthart-Jongbloed K, de Mendonça Melo M, Wever PC, McCall MB, Koelewijn R, van Hellemond JJ, van Genderen PJ:
Predictive value of lymphocytopenia and the neutrophil-lymphocyte count ratio for severe imported malaria. Malar J 2013, 12:101. doi:10.1186/1475-2875-12-101.

49. Schwartz KL, Darwish I, Richardson SE, Mulvey MR, Thampi N: Severe clinical outcome is uncommon in Clostridium difficile infection in children: a retrospective cohort study. BMC Pediatr 2014, 14:28. doi:10.1186/1471-2431-14-28

doi:10.1186/1475-2875-13-61

Cite this article as: Martins et al: Vivax malaria in an Amazonian child with dilated cardiomyopathy. Malaria Journal 2014 13:61.

\section{Submit your next manuscript to BioMed Central and take full advantage of:}

- Convenient online submission

- Thorough peer review

- No space constraints or color figure charges

- Immediate publication on acceptance

- Inclusion in PubMed, CAS, Scopus and Google Scholar

- Research which is freely available for redistribution

Submit your manuscript at www.biomedcentral.com/submit
C) Biomed Central 